\title{
Stocktaking the environmental coverage of a continental ecosystem observation network
}

\author{
Greg R. Guerin (D) ${ }^{1}{ }^{\dagger} \uparrow$ Kristen J. Williams, ${ }^{2}$ Ben Sparrow, ${ }^{1}$ and Andrew J. Lowe ${ }^{1}$ \\ ${ }^{1}$ School of Biological Sciences, The University of Adelaide, Adelaide, South Australia 5005 Australia \\ ${ }^{2}$ CSIRO Land and Water, Canberra, Australian Capital Territory 2601 Australia
}

Citation: Guerin, G. R., K. J. Williams, B. Sparrow, and A. J., Lowe. 2020. Stocktaking the environmental coverage of a continental ecosystem observation network. Ecosphere 11(12):e03307. 10.1002/ecs2.3307

\begin{abstract}
Field-based sampling of terrestrial habitats at continental scales is required to build ecosystem observation networks. A key challenge for detecting change in ecosystem composition, structure, and function within these observatories is to obtain a representative sample of habitats. Representative sampling across a continent contributes to ecological validity when analyzing spatially distributed data. However, field resources are limited, and actual representativeness may differ markedly from theoretical expectations. Here, we report a post hoc evaluation of the coverage of environmental gradients as a surrogate for ecological representativeness by a continental-scale survey undertaken by the Australian Terrestrial Ecosystem Research Network (TERN). TERN's surveillance program maintains a network of ecosystem observation plots initially established in the rangelands through a stratification method (clustering of bioregions by environment) and application of the Ausplots survey methodology. Subsequent site selection comprised gap-filling and opportunistic sampling. We confirmed that environmental coverage was a good surrogate for ecological representativeness. The cumulative sampling of environments and plant species composition over time were strongly correlated (based on mean multivariate dispersion; $r=0.93$ ). We compared environmental sampling of Ausplots to 100,000 background points and a set of retrospective (virtual) sampling schemes: systematic grid, simple random, stratified random, and generalized randomtessellation stratified (GRTS). Differences were assessed according to sampling densities along environmental gradients, and multivariate dispersion. Ausplots outperformed systematic grid, simple random, and GRTS in coverage of environmental space (Tukey HSD of mean dispersion, $P<0.001$ ). GRTS site selection obtained similar coverage to Ausplots when employing the same bioregional stratification. Stratification by climatic zones generated the highest environmental coverage $(P<0.001)$, although resulting sampling densities over-represented mesic coastal habitats. The Ausplots bioregional stratification implemented under practical constraints represented complex environments well, compared to statistically oriented or spatially even samples. Potential statistical power also depends on replication, unbiased site selection, and accuracy of field measurements relative to the magnitude of change. Consistent with previous studies, our stocktake analysis confirmed that environmental, rather than spatial, stratification is required to maximize ecological coverage across continental ecosystem observation networks, and the approach to establishing TERN Ausplots was robust. We recommend targeted gap-filling to complete sampling.
\end{abstract}

Key words: ecological monitoring; environmental sampling; generalized random-tessellation stratified; multivariate dispersion; observatory network; sampling strategy; stratified random sampling; systematic sampling.

Received 1 July 2020; accepted 8 July 2020; final version received 21 August 2020. Corresponding Editor: Debra P. C. Peters.

Copyright: (c) 2020 The Authors. This is an open access article under the terms of the Creative Commons Attribution License, which permits use, distribution and reproduction in any medium, provided the original work is properly cited.

† E-mail: greg.guerin@adelaide.edu.au 


\section{INTRODUCTION}

Global environmental challenges have led to a demand for broadscale information on the distribution, status, and trajectory of biodiversity (Wessels et al. 1998, Watson and Novelly 2004, Scholes et al. 2008, Cleverly et al. 2019). Ecosystem observation networks typically aim to collect standardized field data at regional to national scales on species composition, vegetation structure, and ecological function and may be focused on survey (e.g., vegetation plots sensu Michalcová et al. 2011, Bruelheide et al. 2018) or monitoring (e.g., surveillance or status and trends sensu Larsen et al. 2008, Eyre et al. 2011, Miller and Mitchell 2014, Sparrow et al. 2020a). Field surveys to establish ecosystem observation networks at national or continental scales, while attempting to cover complex ecological variation, can realistically only aim to sample a tiny fraction of the land (Michaelsen et al. 1994). For example, directly monitoring just one hundredth of one percent of the land mass of Australia would require something in the order of an (unrealistic) eight million onehectare plots. It follows that the selection of a finite set of survey sites needs to be efficient and strategic (Austin and Heyligers 1989, Michaelsen et al. 1994, Wessels et al. 1998, Roleček et al. 2007, Hoffman et al. 2013, Barnett et al. 2018).

A key attribute of a network of widely distributed ecosystem observation plots is the degree to which it has an ecologically representative design, meaning it includes samples across the diversity of ecosystems (including their underlying environments and constituent species) and their geographic occurrences (Hoffman et al. 2013, Metzger et al. 2013). Representative sampling networks are needed to comprehensively capture the variety of ecological communities over large areas without bias to particular systems (Roleček et al. 2007). Such networks have been implemented effectively to provide spatial surveys of above- and below-ground biodiversity (Bastin et al. 2017, Lemetre et al. 2017, Baruch et al. 2018) and to monitor ecosystem condition in relation to disturbance, land use, and climate change (Hoekman et al. 2017, McCord et al. 2017, Barnett et al. 2019).
The strategic placement of a limited number of field plots could be implemented in many different ways, ranging between the extremes of incautious practicality and statistical purism (Roleček et al. 2007, Hoffman et al. 2013). Survey and monitoring networks have been established, for example, using systematic grid (Messer et al. 1991, Goring et al. 2016), stratified random (Michaelsen et al. 1994, Danz et al. 2005, Carvalho et al. 2016, Hoekman et al. 2017, van Etten and Fox 2017), gradsect (Austin and Heyligers 1989, Wessels et al. 1998), and generalized random-tessellation stratified (GRTS; Larsen et al. 2008, McCord et al. 2017, van Dam-Bates et al. 2018) designs. While purely random surveys are more statistically robust, they require a larger sample size and have been shown to be less effective at capturing ecological diversity, which is typically structured along multiple environmental gradients (Austin and Heyligers 1989, Wessels et al. 1998, Roleček et al. 2007, Michalcová et al. 2011, Carvalho et al. 2016, CaddyRetalic et al. 2017).

In contrast to more statistically rigorous designs, many regional scale surveys of terrestrial ecosystems have often employed so-called preferential sampling as a way to include examples of as many habitats as possible (Michalcová et al. 2011). Although preferential sampling deliberately captures rare ecological communities that may be missed by systematic sampling designs, in doing so, it may fail to meet the assumptions of certain statistical tests to support broader inference (Roleček et al. 2007).

Here, we assess the performance of a real network of monitoring sites-the Terrestrial Ecosystem Research Network's (TERN) Ausplots-in terms of representativeness by comparing its environmental coverage with that of virtual plot networks based on alternative, retrospective sampling schemes. TERN is Australia's multiscale ecosystem observation platform that combines remote sensing, distributed field surveys and eddy covariance flux towers to measure responses to drivers such as climate change and variability, and fire (Cleverly et al. 2019). Ausplots are TERN's field monitoring sites located across Australia that have been sampled using a consistent method involving quantitative 
measurements of vegetation and characterization of soils (White et al. 2012, Guerin et al. 2017, Cleverly et al. 2019, Sparrow et al. 2020b). Ausplots sites form a continent-wide ecosystem surveillance monitoring network comprising more than 700 fixed locations, with a gap-filling goal to achieve around 1000 .

We describe the stratification method used to determine the locations of Ausplots. We then consider how well the environment heterogeneity of Ausplots locations (Christianson and Kaufman 2016) acts as a surrogate for their observed ecological diversity (Albuquerque and Beier 2018). Our assessment is relevant internationally to the implementation of new monitoring networks and to the application of data from existing networks built under various sampling strategies.

We address the following questions: (1) What is the environmental coverage of Ausplots locations? (2) Is environmental heterogeneity a good surrogate for species diversity? (3) How well do the Ausplots locations perform in terms of their environmental coverage compared to retrospective sampling schemes?

\section{Methods}

\section{The Ausplots study design}

The procedure used to select Ausplots sites is scalable, used the best available spatial information in a particular area, and was nationally consistent (Box 1). The procedure was based on: (1) stratification of bioregions using a hierarchical cluster analysis (Appendix S1: Fig. S1) and selection of priority bioregions; (2) plot stratification within each selected bioregion based on, for example, major vegetation groups or land units; and (3) assessment of the homogeneity of selected areas of interest and availability of historical data. The process of stratified sampling used to locate sites across Australian bioregions relied upon the Australian terrestrial bioregions (known as IBRA; Thackway and Creswell 1995, Department of the Environment 2012), a nationally agreed classification system that defines areas with distinctive biophysical environmental characteristics (Williamson et al. 2011). Sampling initially focused on the Australian rangelands (Sparrow et al. 2020b) and tall eucalypt forests (Wood et al. 2015), before the scope was widened to include all terrestrial ecosystems.

\section{Box I.}

\section{The original Ausplots stratification}

\section{Stage One. Bioregional stratification}

Stratification was applied to Australian bioregions (Thackway and Creswell 1995, Department of the Environment 2012), including 50 in the rangelands, the initial focus of Ausplots. Plots were located in bioregions that provided diverse geographic and environmental representation of vegetation structure and composition at relevant scales. To prioritize bioregions, spatial layers were used in hierarchical cluster analyses to group similar bioregions. Variables included:

1. climate (Hutchinson agro-climatic classes, Hutchinson et al. 2005);

2. regolith (Regolith of Australia, Craig 2013);

3. the broadest relevant geological classification in Australia, incorporating landscape and relief class;

4. major vegetation groups (National Vegetation Information System (NVIS) Level 3; ESCAVI 2003); and

5. the rangelands boundary and the IBRA 6.1 sub-bioregion boundaries.

Results were interpreted by examining the length of branches joining bioregions on the dendrogram and the degree of similarity (length of branches) of neighboring bioregions. The analysis identified 36 groups of bioregions, of which 21 occurred within the rangelands.

\section{Stage Two. Selecting representative bioregions}

The aim was to sample at least one bioregion per group, based on: 


\section{(Box 1. Continued)}

1. logistical issues such as land use, extent of reserve-tenure land, and ease of access;

2. the need for widespread spatial coverage of the bioregion;

3. state agency priorities and capacity to support surveys;

4. data gaps (where little previous information exists);

5. areas where co-locating with existing sites increases the utility of site access/ownership and security; and

6. the likelihood of longevity of site management for monitoring purposes.

In addition to bioregional stratification, Ausplots subsequently incorporated sampling stratified along four preexisting regional climatic transects (Caddy-Retalic et al. 2017), as well as plot locations determined by various collaborations. Precise plot locations were identified using Stages 3 and/or 4 of the stratification below.

\section{Stage Three. Stratifying areas of sampling interest within selected bioregions}

An additional stratification was conducted to select areas of interest within the bioregion. This was based on a hierarchical process that commenced with a GIS desktop exercise to interrogate available spatial information and identify potential areas of interest. Guidelines were employed in this process, but flexibility was necessary in choosing plot locations, and potential locations often needed to be visited to determine suitability. Unavoidable fiscal and logistical constraints meant that a practical design that maximized the likelihood of meeting broad objectives was preferred to a theoretically optimal or random sampling design.

1. Level 1: IBRA sub-regions-Each IBRA bioregion was divided into sub-regions that describe the variety of land types within the bioregion. These are used as the first level in the plot stratification hierarchy.

2. Level 2: Land systems - areas with recurring patterns of landform, soils, and vegetation that are related geographically and geomorphologically with a similar position in the landscape/catchment.

3. Level 3: Disturbance regime-sampling targeted areas that represent benchmarks (Landsberg and Crowley 2004). Sites in undisturbed environments are ideal for monitoring long-term ecosystem change. However, much of the rangeland environment has been disturbed to some extent. The stratification process identified areas of least disturbance, based on the concept of best on offer.

4. Level 4: History-Australian State and Territory jurisdictions have biodiversity inventory programs with useful baseline data on plant and animal distributions collected in some parts of the rangeland. These were incorporated if available. A further consideration was the land management history of an area and the availability of any previous monitoring of that land management. Information important in deciding whether or not any previous monitoring is relevant and compatible included:

a. ability to relocate the site;

b. monitoring methods used and compatibility, quality, consistency, availability, and completeness of data;

c. availability of curated voucher specimens;

d. time period and frequency for which monitoring was undertaken.

\section{Stage Four. Choosing plot location in the field based on areas of interest}

Stages One to Three of the stratification determined priority areas within which plots should be located but these not precise plot locations. Decisions about where to place a plot within the area of interest were made in the field based on considerations such as being in representative of the selected ecological community and homogeneous enough to comfortably accommodate a one-hectare plot within consistent vegetation, slope, relief, and soil.

\section{Datasets}

The Ausplots field sampling protocols and datasets have been described previously (White et al. 2012, Wood et al. 2015, Guerin et al. 2017,
Sparrow et al. 2020b). Here, we focus mainly on the spatial sampling of the plot network as a whole rather than the measurements taken. We used information on plant species composition 
a)

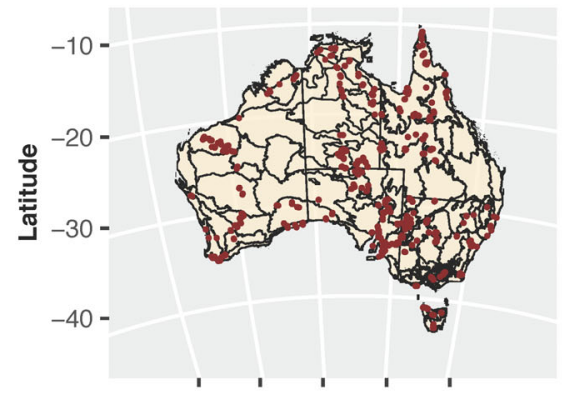

c)

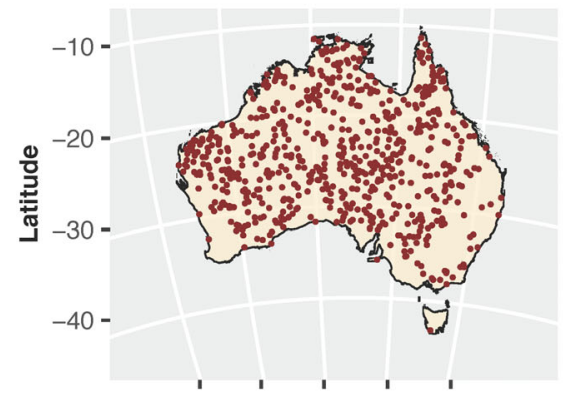

e)

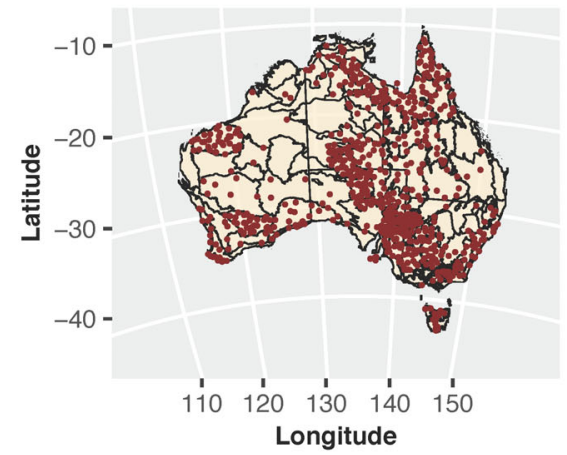

b)

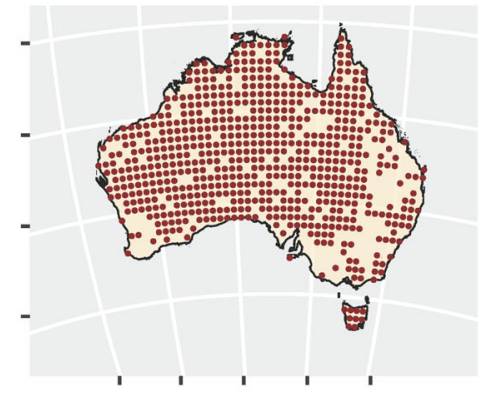

d)

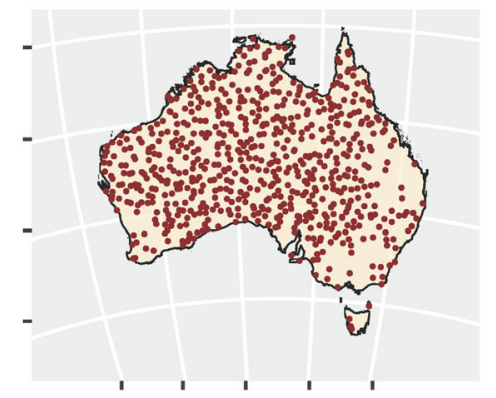

f)

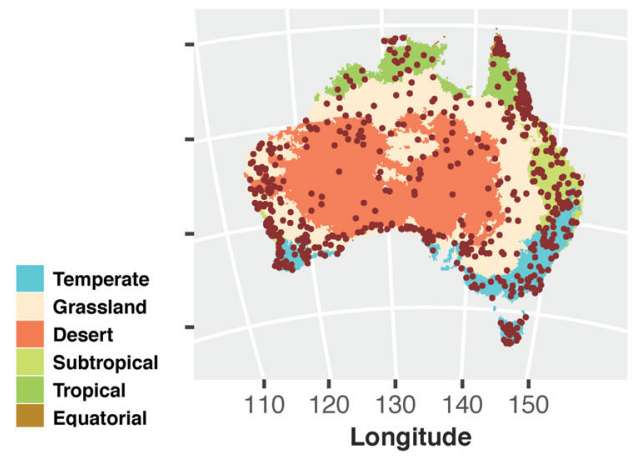

Fig. 1. Locations of real and virtual monitoring sites across Australia representing alternative sampling strategies. Available locations were restricted to areas considered natural, that is, excluding completely anthropogenically modified habitats: (a) 650 Ausplots included in the analysis over a base map of Australia showing the IBRA bioregions used to stratify the original sampling; (b) systematic grid; (c) simple random; (d) stochastic spatially balanced (generalized random-tessellation stratified: GRTS); (e) GRTS stratified to the same density in IBRA regions as Ausplots; (f) random stratified by Köppen climate zones - 24 zones were used but only the six major zones are shown on the base map for clarity.

recorded within plots to compare taxonomic sampling to environmental sampling. Plot location and vegetation voucher (vascular plant species herbarium determinations) data were sourced through the ausplotsR package (TERN 2018, Guerin et al. 2020a). Data for 650 plots available at the time of analysis were included in the assessment of environmental coverage (Fig. 1). A subset of 580 plots were used to analyze cumulative species sampling-those for which fully processed composition data were available at that time. The composition data are a complete floristic inventory of species detected visually within each one-hectare plot, with 
identifications verified from voucher specimens lodged at major State or Territory herbaria according to a standardized taxonomy.

A set of 25 gridded, 9-second resolution climate surfaces were sourced from Harwood et al. (2016, Williams et al. 2010, 2012) and are based on a thirty-year average during 1976-2005. Climate variables included monthly minima and maxima and annual mean for temperature, precipitation, evaporation, aridity, and water deficit (Appendix S1: Table S1). Soil and landform variables at 9-second resolution were sourced from Gallant et al. (2018) and are aggregated versions of the 3-second Soil and Landscape Grid of Australia (Viscarra-Rossel and Chen 2011, Viscarra Rossel et al. 2014, 2015, Grundy et al. 2015, Appendix S1: Table S2). Soil variables covered structure, texture, chemical content, and $\mathrm{pH}$. Landform variables included slope, curvature, and elevation range.

\section{Environmental coverage as a surrogate for ecological coverage}

TERN's ecosystem observation networks aim to represent a range of terrestrial habitats and therefore maximize species coverage. Before embarking on analysis of environmental sampling coverage, we assessed whether environmental heterogeneity has been a useful surrogate for ecological diversity of Ausplots. We assessed plant species composition data from field plots in the chronological order they were surveyed. Treating successive plots as additions to a cumulative sample of environmental and ecological space, we calculated pairwise Euclidean distances (environmental variables)/Sörenson dissimilarities (species composition), respectively, among plots and calculated the multivariate dispersion (distance to group centroid in principal coordinate space) of the cumulative samples as plots were added. We compared the cumulative mean between environmental and ecological (species composition) datasets. We plotted cumulative dispersion scores against samples for each dataset together and reported the Pearson correlation coefficient $(r)$ to supplement visual interpretation of the correspondence between cumulative environmental versus ecological sampling coverage. We used a chronological order accumulation curve and not rarefaction partly to reflect the nature of the sampling as expeditions, and partly because the response of interest was the correlation between environmental and ecological accumulation rather than the expected amount of either at a given a level of sampling.

\section{Retrospective sampling strategies}

Our approach to assessing the performance of the Ausplots network in environmental space was to compare real-world survey locations to a series of virtual retrospective sampling strategies as well as randomly selected background points for Australia (Table 1). We selected the same number of retrospective virtual sites (i.e., 650) as Ausplots locations (Fig. 1). To ensure sites were not selected in environmental space that was not available in practice, we masked Australia to areas mapped as natural, which excludes areas considered mainly anthropogenically modified such as urban areas or agricultural paddocks (Department of the Environment 2014).

Systematic grid sampling involved sampling along a regular longitude/latitude grid spaced at 0.9 degrees, representing the mostly spatially even sampling possible. Simple random sampling involved the sampling of random spatial coordinates. For stratified random sampling, we sampled an even number of random coordinates within strata defined by climatic zones based on modified Köppen zones (Stern et al. 2000; http:// www.bom.gov.au/climate/averages/climatology/ gridded-data-info/metadata/md_koppen_classif ication.shtml, accessed 14 November 2019). Three climate zones represented by $<150$ pixels $\left(0.025^{\circ}\right)$ were excluded, leaving 24 zones. Generalized random-tessellation stratified (GRTS) sampling is a stochastic but spatially balanced survey design which can be loosely described as a compromise between grid and random sampling in terms of the chance of a site being sampled and resulting spatial evenness. All locations have a chance of being selected, yet the sampling is more even than random sampling. Finally, we applied GRTS sampling to stage 3 of the original stratification process for Ausplots. That is, we employed the same density of plot sampling within selected bioregions as Ausplots but used GRTS to select virtual sites within those regions, to compare the environmental coverage when using a systematic sampling scheme at a finer level of stratification only. We chose GRTS for 
Table 1. Explanation of sampling strategies tested, comparing TERN Ausplots to alternative, retrospective schemes.

\begin{tabular}{|c|c|c|c|c|}
\hline Figure code & Name & Sampling strategy & Advantages & Limitations \\
\hline Background & Background & $\begin{array}{l}\text { 100,000 randomly selected } \\
\text { points across Australia for } \\
\text { comparison }\end{array}$ & $\ldots$ & $\ldots$ \\
\hline Ausplots & $\begin{array}{l}\text { TERN } \\
\text { Ausplots }\end{array}$ & $\begin{array}{l}\text { Classification of bioregions by } \\
\text { environment; selection of } \\
\text { priority bioregions; further } \\
\text { stratification within selected } \\
\text { bioregions; pragmatic site } \\
\text { selection. }\end{array}$ & $\begin{array}{l}\text { High environmental } \\
\text { stratification while } \\
\text { accounting for access } \\
\text { issues (e.g., resources, } \\
\text { remoteness, land tenure). }\end{array}$ & $\begin{array}{l}\text { Preferential local site selection } \\
\text { may break assumptions of } \\
\text { some statistical methods. }\end{array}$ \\
\hline Grid & $\begin{array}{l}\text { Systematic } \\
\text { grid }\end{array}$ & $\begin{array}{l}\text { Plots are located along a } \\
\text { predetermined grid. }\end{array}$ & $\begin{array}{l}\text { Maximizes spatial } \\
\text { evenness. }\end{array}$ & $\begin{array}{l}\text { Any one site determines the } \\
\text { locations of all other sites. } \\
\text { Inefficient environmental } \\
\text { coverage. }\end{array}$ \\
\hline Random & $\begin{array}{l}\text { Simple } \\
\text { random }\end{array}$ & $\begin{array}{l}\text { Sites are located at randomly } \\
\text { selected coordinates. }\end{array}$ & Statistically robust. & $\begin{array}{l}\text { Spatially uneven. Inefficient } \\
\text { environmental coverage. }\end{array}$ \\
\hline GRTS & $\begin{array}{l}\text { Generalized } \\
\text { random- } \\
\text { tessellation } \\
\text { stratified } \\
\text { (GRTS) }\end{array}$ & $\begin{array}{l}\text { A combination of stochastic site } \\
\text { selection with spatially } \\
\text { balanced design. }\end{array}$ & $\begin{array}{l}\text { Statistically robust. More } \\
\text { even than random. }\end{array}$ & $\begin{array}{l}\text { Inefficient environmental } \\
\text { coverage. }\end{array}$ \\
\hline GRTS-strat & $\begin{array}{l}\text { GRTS with } \\
\text { bioregional } \\
\text { stratification } \\
\text { matching } \\
\text { Ausplots }\end{array}$ & $\begin{array}{l}\text { GRTS site selection is applied to } \\
\text { a predetermined density of } \\
\text { plots within bioregions. }\end{array}$ & $\begin{array}{l}\text { The bioregional } \\
\text { stratification process of } \\
\text { Ausplots increases } \\
\text { environmental coverage. } \\
\text { Statistically robust. }\end{array}$ & $\begin{array}{l}\text { Some practical limitations to } \\
\text { implementation (i.e., site } \\
\text { access). }\end{array}$ \\
\hline Stratified & $\begin{array}{r}\text { Stratified } \\
\text { random }\end{array}$ & $\begin{array}{l}\text { An even number of randomly } \\
\text { selected plots are stratified } \\
\text { among } 24 \text { climatic zones. }\end{array}$ & $\begin{array}{l}\text { Environmental coverage is } \\
\text { very high. Local site } \\
\text { selection is statistically } \\
\text { robust. }\end{array}$ & $\begin{array}{l}\text { Resulting sampling densities } \\
\text { along environmental } \\
\text { gradients are a poor match for } \\
\text { background because mesic } \\
\text { habitats are over-represented. }\end{array}$ \\
\hline
\end{tabular}

this analysis because it balances random and spatially even sampling.

For Ausplots and retrospective sampling schemes, we extracted climate, soil, and landform data from the spatial data layers at plot locations (Data S1). The extracted environmental data were the basis of the univariate, bivariate, and multivariate analyses of environmental sampling coverage outlined below.

\section{Assessment of environmental coverage}

Univariate.-The aim was to assess sampling intervals along gradients and test whether sampling density at different points along the gradients was comparable to the available background environment, which would be expected of a representative sample. For individual environmental gradients (layers), we assessed the distribution of sampling by preparing density plots for each sampling scheme. Sampling density for each scheme was over-plotted with the background density for Australia based on extracted values of environmental variables at 100,000 random locations selected from within "natural" areas.

Bivariate.-We visualized environmental coverage of alternative sampling schemes over the background of Australia (100,000 random points) using bivariate scatterplots of selected, ecologically relevant variables. The variables related to temperature, precipitation, topography and soil texture, and nutrient status.

Multivariate.-Using an approach similar to the surrogacy test above, we used multivariate dispersion to assess the environmental coverage of Ausplots compared to the retrospective sampling strategies. In this instance, we included all plot locations together rather than examining cumulative sampling as plots were added. Samples in each scheme (Ausplots or virtual) were scored by their distance to group centroid in multivariate environmental space as represented by principal coordinates (multi-dimensional scaling (MDS) of scaled Euclidean distances). We removed 
environmental variables that were highly collinear by setting VIF (variance inflation factors) to below 10. The resulting subset of the data contained 26 variables out of the original 44 , including 10 of the 25 climate variables, 10 of the 12 soil variables, and six of the seven landform variables.

We assessed the distribution of distances of individual plots from their group centroid and calculated the mean distance to centroid in multivariate (PCoA) environmental space. Additionally, we tested for significant differences among the mean distances to group centroids for each scheme using a bespoke permutation test (with 1000 replications) followed by a post hoc multivariate implementation of the Tukey HSD test to make pairwise comparisons (Oksanen et al. 2018). Environmental coverage was interpreted as higher when mean dispersion was higher.

\section{Software}

Analyses were undertaken in R (version 3.5.1; R Core Team 2016; Data S1). Key R packages used to perform the analyses were spsurvey, vegan, ausplotsR, and raster (Kincaid and Olsen 2017, Hijmans 2018, Oksanen et al. 2018, Guerin et al. 2020a).

\section{RESULTS}

\section{Environmental heterogeneity as a surrogate for ecological diversity}

The environmental heterogeneity of samples, as assessed via multivariate dispersion, was a good surrogate for the ecological diversity of a cumulative sample of Ausplots floristic surveys (Fig. 2; Pearson's $r=0.93$ for cumulative means). The result suggests the amount of environmental space sampled relates closely to the beta diversity of species sampling (Anderson et al. 2006). This supported the premise that we can use environmental heterogeneity as a surrogate for ecological diversity, given limited sampling of biodiversity, but relatively complete information on macro-environment, at virtual or background sites.

\section{Assessment of environmental coverage}

Univariate.-The comparative densities of sampling along univariate environmental gradients in the context of background points across

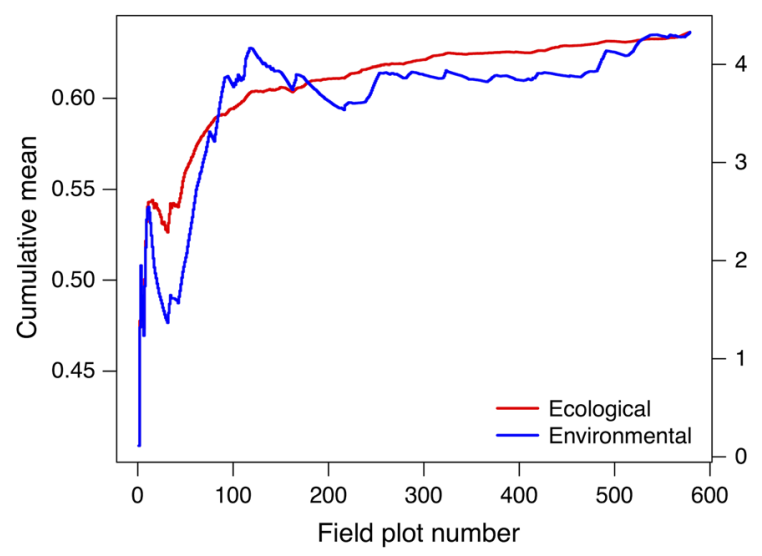

Fig. 2. Environmental coverage as a surrogate for ecological coverage: cumulative sampling of environmental (right $y$-axis, based on Euclidean distance for scaled environmental variables) and ecological (left $y$ axis, based on Sörenson dissimilarity for plant species composition) space, represented as the cumulative mean of multivariate dispersion of plots around their group centroid in principal coordinate space, in the chronological order they were sampled. The correlation between cumulative sampling of environment and species composition ( $r=0.93$ for the mean) suggests environmental coverage is a reasonable surrogate for species representation.

Australia are shown in Fig. 3 and Appendix S1: Fig. S2. Grid, random, and GRTS strategies produced sampling densities that were very similar across all gradients and were also a close match to background points. Ausplots and GRTS-strat sampling densities were very similar to each other, and somewhat similar to background, although sampling at slightly higher densities within cooler, wetter, and less sandy habitats (Fig. 3), while the stratified strategy was strongly skewed in the same way, relative to background points. Although the environmental gradient intervals sampled were comparable across schemes and background points, there were some differences in the coverage of environmental extremes (Data S1). Ausplots ranked last in sampling the minima and maxima of gradients, whereas the stratified strategy ranked first.

Bivariate.-Sampling scatterplots for selected gradients and their context against background points for Australia are shown in Fig. 4. Each of the sampling strategies resulted in reasonable 
coverage of Australian environments. However, the environmentally stratified schemes (Ausplots, GRTS-strat, and stratified) better captured the extremes of that space. For example, stratified captured warm and very wet habitats (i.e., the wet tropics), and, along with Ausplots and GRTS-strat, the coldest of Australian habitats (Fig. 4).

Multivariate.-A plot showing the first two axes of a principal coordinates analysis (i.e., PCoA or MDS) and distances to sampling scheme group centroids is shown in Fig. 5. The relative position of the group's centroids reflects differences in sampling of environmental space that are also visible from bivariate plots in Fig. 4.

The size of the sampled environmental space (visualized in Fig. 5) is measured via the distance of each plot to its group centroid in PCoA space. The respective distribution, mean, median, and variance of these distances are visualized in Fig. 6. There were significant differences between the means (permutation test, $P<0.01$ ), resulting in three groupings as follows (in ascending order; pairwise TukeyHSD $P<0.001$ ): (1) random, GRTS, grid; (2) GRTS-strat, Ausplots; and (3) stratified.

\section{Discussion}

Any number of spatial sampling schemes satisfying strict statistical criteria can be designed via desktop analysis that would be challenging to implement as large-scale observation networks. For example, large areas of Australia (especially the inland) are remote in terms of distance to population centers and access by road (Austin and Heyligers 1989). Land tenure (e.g., defense lands) and security of long-term access further limit sample locations for fixed plots to be periodically revisited. Moreover, given resource limitations, the expense and, in some cases, bureaucratic processes, involved in reaching statistically predefined, and often remote, locations need strong justification from a monitoring perspective. In such circumstances, idealized sampling must be tempered with logistical pragmatism (Austin and Heyligers 1989).

One facet of a surveillance monitoring network that makes it useful as a large-scale ecological observatory (Schimel 2011) is representativeness (Hoffman et al. 2013, Metzger et al. 2013). That is, the degree to which it effectively samples the diversity of habitats without skewing toward environmentally unique systems of a small spatial extent. TERN Ausplots were initially stratified across environments by selecting bioregions representing environmental clusters (Box 1). Here, we assessed how the environmental coverage of Ausplots compared to the same number of plots located retrospectively via alternative random, systematic, or stratified strategies.

\section{What is the environmental coverage of Ausplots?}

The spatial sample of Ausplots resulted from a process of selecting a subset of rangelands bioregions that were representative of environmentally similar clusters (Box 1). A further 48 plots were in tall eucalypt forests (Wood et al. 2015). The initial stratification of rangelands bioregions was followed by a pragmatic site selection process, targeted gap-filling (expanding the scope of sampling beyond the rangelands), incorporation of regional climatic transects (Caddy-Retalic et al. 2017), and opportunistic sampling; the latter arising from collaborations with stakeholders in particular regions. We confirmed that the suite of Ausplots locations effectively sampled the environments of Australia in terms of the range and density of sampling along soil, landform, and climatic gradients compared to randomly selected background locations (Figs. 3 and 4; Appendix S1: Fig. S2). The Ausplots locations cover the full range of these gradients without over-representing outlier environments.

\section{Has environmental coverage been a good surrogate for species coverage?}

Without prior knowledge of the species that would be sampled at potential monitoring sites, we relied on environmental differences as a surrogate for expected ecological differences (Albuquerque and Beier 2018, Ware et al. 2018). However, different vegetation may occur in similar macro-environments (Bruelheide et al. 2018). Using existing Ausplots survey data, we empirically confirmed that sampling a larger environmental space resulted in corresponding increases in the capture of ecological beta diversity (Anderson et al. 2006), making environmental coverage a useful surrogate. However, we did not exclude strictly spatial effects from this assessment. Some of the ecological turnover among sites in 
GUERIN ET AL.

a)

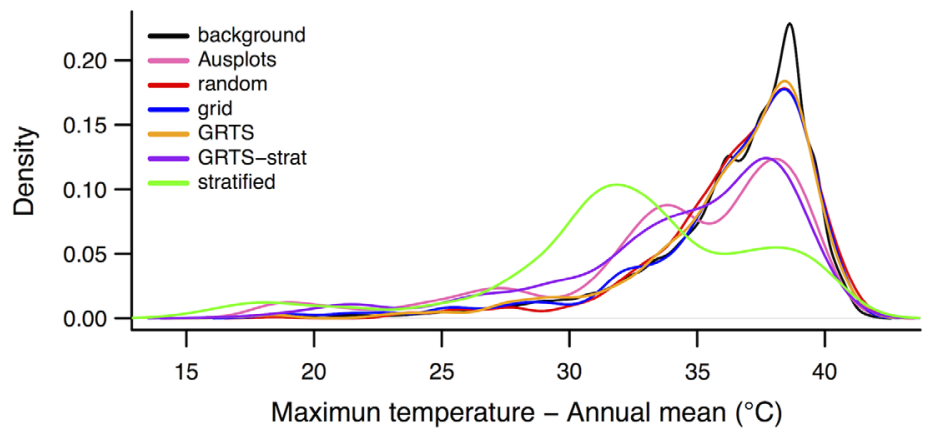

b)

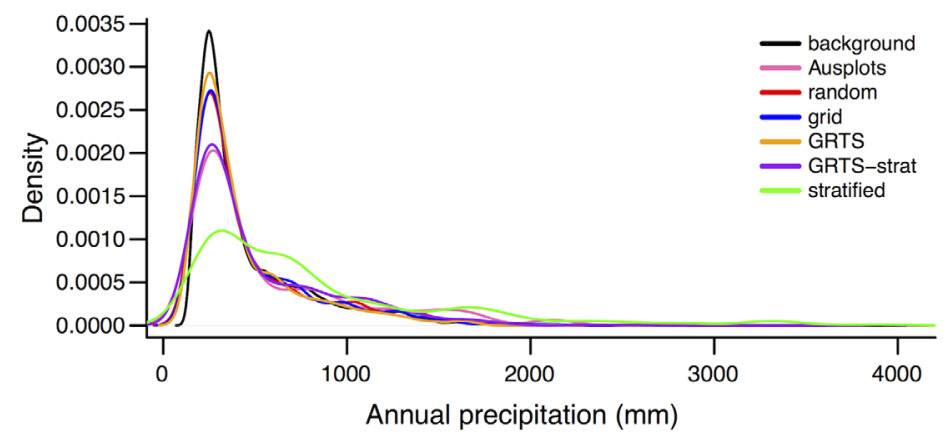

c)
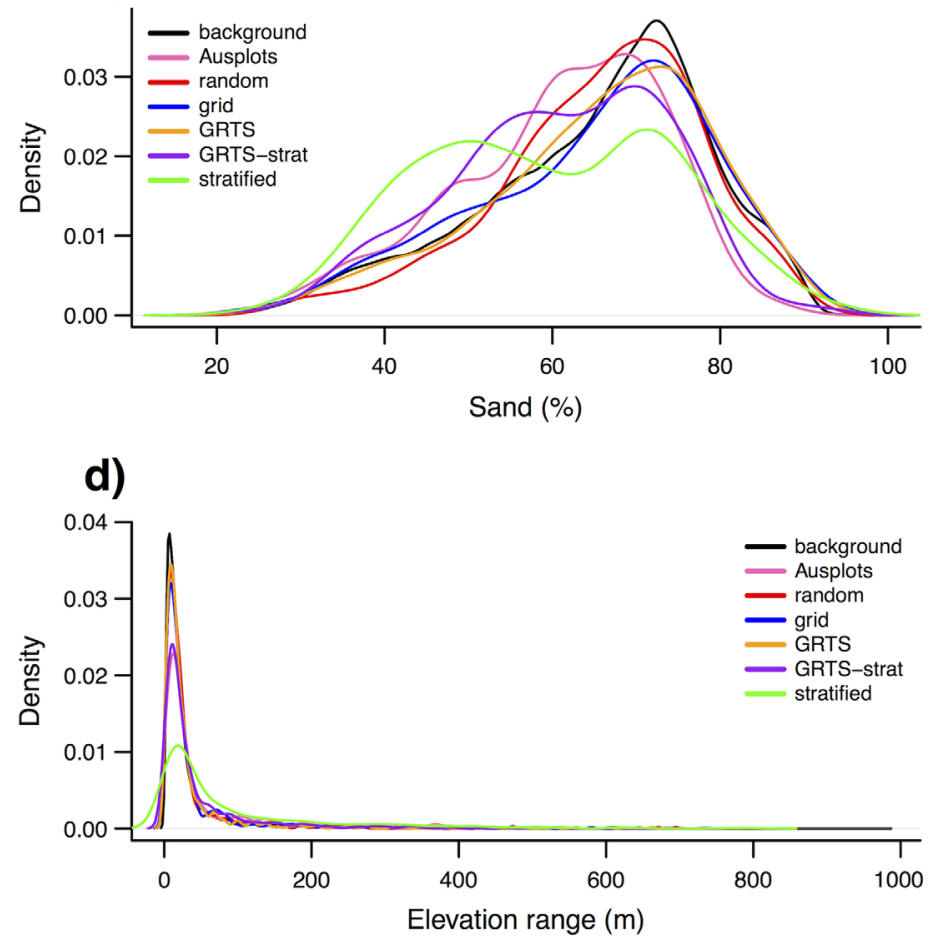

Fig. 3. Univariate density plots showing the relative intensity of sampling along selected individual 
(Fig. 3. Continued)

environmental gradients in the context of background points for Australia and comparing Ausplots to retrospective schemes (legend): (a) annual mean of maximum temperature; (b) annual precipitation; (c) soil sand; and (d) elevation range within $1000 \mathrm{~m}$. Equivalent plots for all 44 environmental variables in the dataset are shown in Appendix S1: Fig. S2. Variables are described in Appendix S1: Tables S1 and S2 and sampling strategies are described in Table 1.

different environments may be caused by the geographic distance between them. In that sense, space itself is generally considered a useful surrogate for ecological and environmental differences, which is why spatially stratified or even sampling strategies have traditionally been more common than explicit environmental stratification (Caddy-Retalic et al. 2017).

\section{How has Ausplots performed compared to retrospective sampling schemes?}

The stratification process used by Ausplots outperformed systematic grid, simple random, and GRTS sampling, but not stratified random sampling, in terms of environmental coverage from a limited set of samples (Fig. 6). While this makes random sampling stratified by climatic zones a more efficient strategy for environmental sampling, there are further considerations. Firstly, Ausplots initially focused primarily on the rangelands of the Australian inland, so it was not surprising to find the wetter coastal habitats underrepresented. Coastal areas were avoided in the early sampling of Ausplots, because the inland of Australia was significantly under-studied (Eyre et al. 2011, Guerin et al. 2017). Secondly, by maximizing coverage of climatic zones with even sampling density, the stratified random strategy may have over-represented more mesic, coastal habitats, as shown by comparison to background points (Fig. 3). The environmental coverage of GRTS was similar to that of Ausplots, when restricted to the same sampling density within bioregions. We conclude that the method of site selection at finer spatial scales is less important for total environmental coverage than stratification at national scales. However, we did not compare environmental coverage within individual bioregions, a scale at which differences may emerge.

All approaches to sampling have advantages and limitations (Table 1). For example, simple random sampling is robust for subsequent statistical inference because each sample is independent and unbiased. However, random locations can be spatially uneven or difficult to access in an efficient way during field campaigns. GRTS provides a compromise between spatial evenness and independence (Stevens and Olsen 2004). A master sample can be prepared in advance from which field sites are measured (van Dam-Bates et al. 2018).

More subjective or preferential strategies may break the assumptions of some statistical methods (Roleček et al. 2007) because each location does not have the same chance of being selected (Lájer 2007). Even so, applying ecological knowledge to the location of field plots can increase the efficiency with which diverse habitats are sampled (Michalcová et al. 2011). The sampling of TERN Ausplots has been shaped partly by sociopolitical, environmental, infrastructure, safety, or resource limitations to access and therefore is a combination of quantitative stratification, targeted coverage of habitat diversity, and practical limitations.

Potential methods for designing the spatial sampling of an ecosystem observatory are practically limitless. We therefore limited comparisons of the Ausplots stratification to relatively simple strategies that have been commonly implemented. More sophisticated algorithms could weight potential locations by distance or accessibility, or seek to iteratively complement the environmental coverage of an accumulating sample (Kumar et al. 2016, Albuquerque and Beier 2018). Indeed, a recent aim of Ausplots sampling has been to gap-fill the network of monitoring plots with surveys targeting regions predicted to be the most ecologically different in a generalized dissimilarity modeling framework (Guerin et al. 2020b).

Maximizing environmental coverage is not the be-all and end-all of sampling, even in terms of representativeness. Ausplots ranked last for sampled gradient minima and maxima (also evident in the lower outliers for Ausplots in Fig. 6), 


\section{a)}
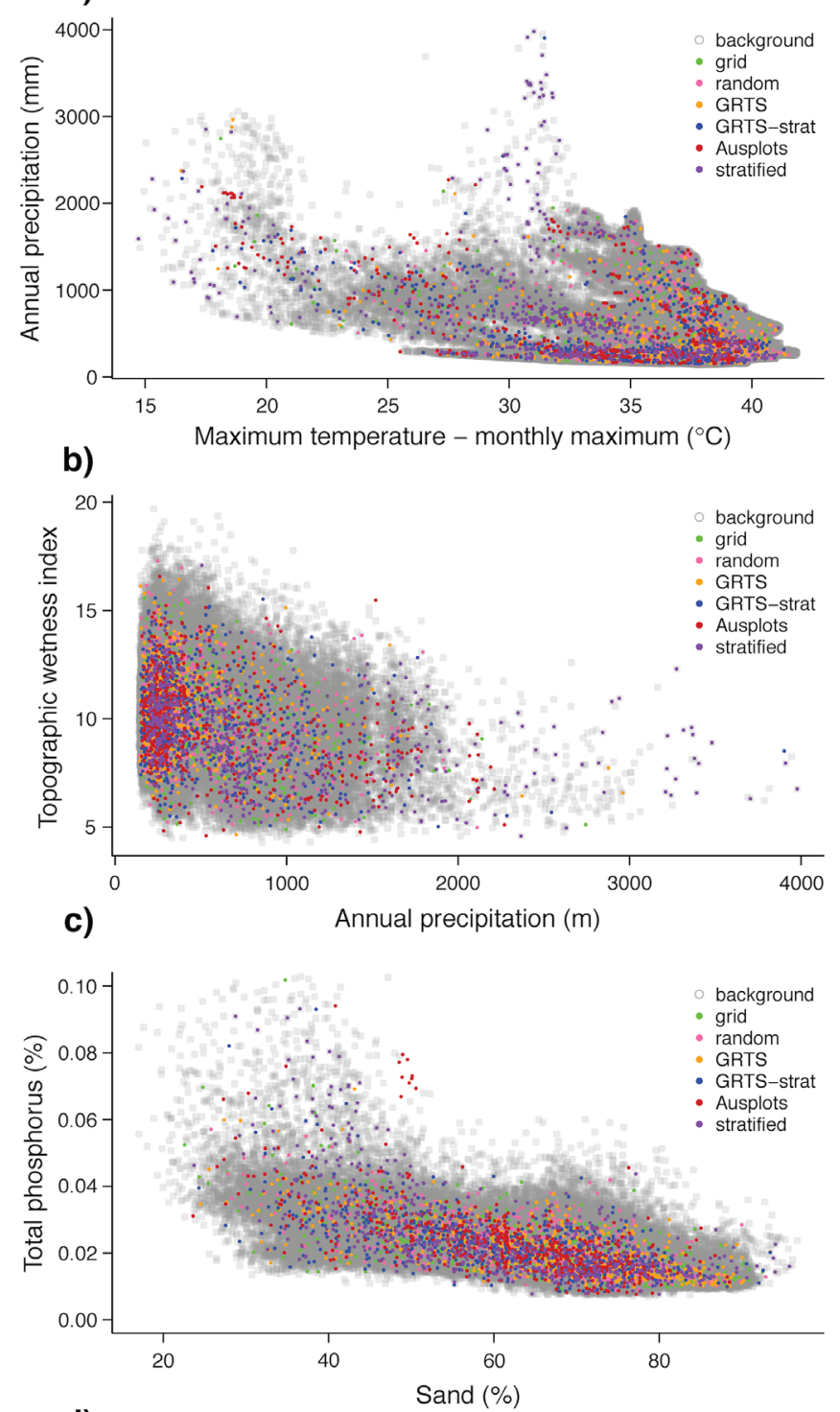

d)

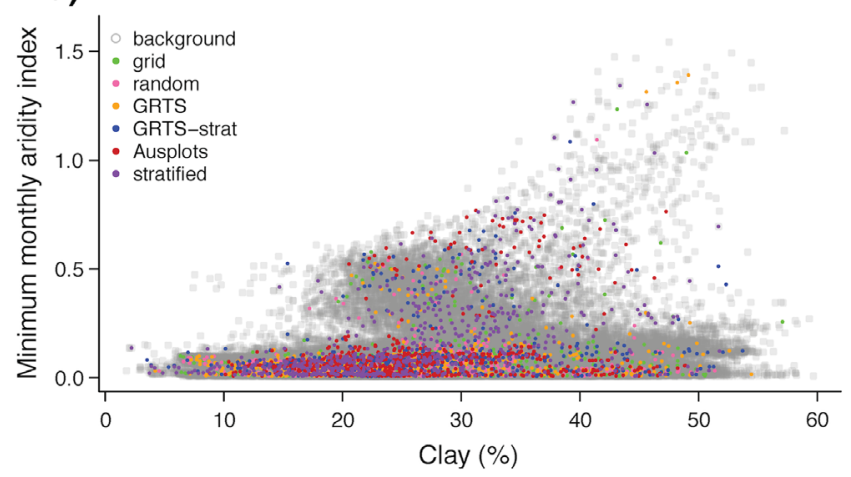

Fig. 4. Scatterplots showing the sampling of background environmental space by Ausplots and retrospective 
(Fig. 4. Continued)

sampling strategies: (a) annual precipitation against maximum temperature-monthly maximum; (b) topographic wetness index against annual precipitation; (c) soil phosphorus against soil sand; and (d) minimum monthly aridity index against soil clay. See Appendix S1: Tables S1 and S2 for variables, Table 1 for descriptions of sampling strategies, and Fig. 1 for spatial arrangement of samples.

although the differences were small in many cases. Stratification by climate zones was more successful at sampling environmental extremes. However, these extremes represent only small spatial extents (relatively rare environments in Australia), indeed the higher environmental coverage of stratification by climate zones corresponded to poorer matches to background densities along environmental gradients. There is also a trade-off between the evenness of spatial versus environmental sampling.

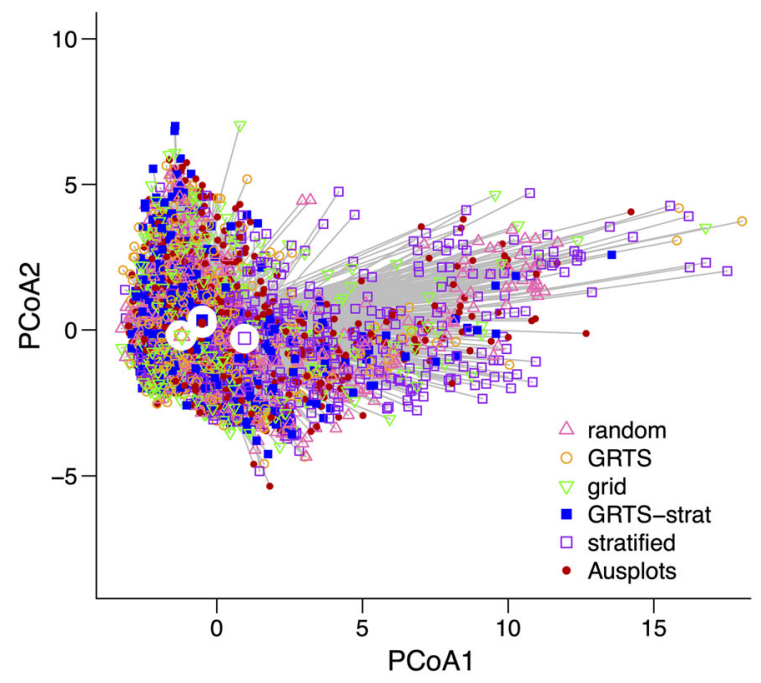

Fig. 5. Multivariate dispersion ordination plot displaying the first two axes of a principle coordinates analysis (PCoA, or MDS) based on Euclidean distances and scaled, non-collinear environmental variables. Group centroids for each scheme are highlighted by white circles. Gray vectors illustrate relationship of each point (plot) to its centroid. Sampling schemes with larger mean distance to group centroid, that is, larger multivariate dispersion, were considered to represent more environmental space. Multivariate dispersion was based on the variables in Appendix S1: Tables S1 and S2. Refer to Table 1 for descriptions of the sampling strategies shown here and Fig. 1 for spatial arrangement of samples.
In addition to spatial extent and coverage of environmental variation, other aspects of a sampling strategy influence the capacity of an observation plot network to effectively detect change. For example, plots could also be stratified across gradients of vulnerability to climate change or natural and human disturbance or fragmentation, which are dynamic (Tuanmu and Jetz 2015, Gallagher et al. 2019). The frequency of temporal sampling, level of local replication, magnitude of changes occurring, accuracy of field-based measurements, and the degree to which samples are unbiased with respect to drivers of interest, influence the power to detect spatial and temporal change at local, regional, and continental scales.

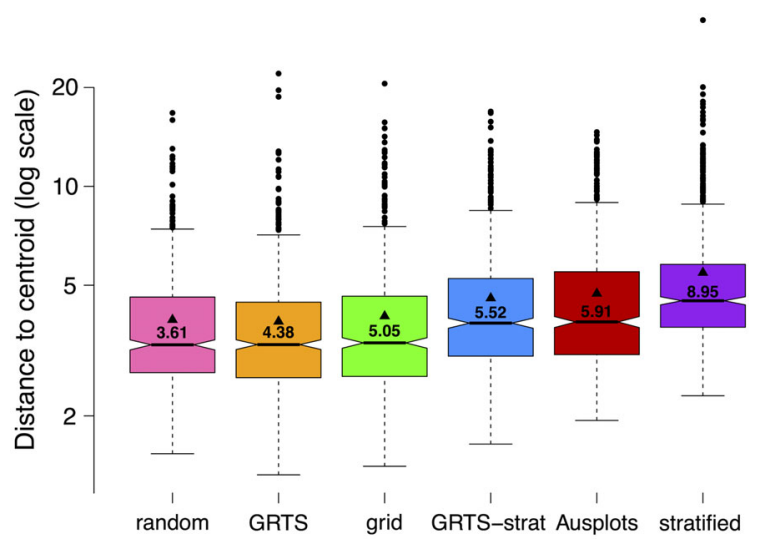

Fig. 6. Multivariate dispersion in environmental space by sampling scheme, comparing Ausplots to retrospective strategies: box (interquartile range) and whisker $(1.5 \times$ interquartile range $)$ plots show the distribution of distance to centroid for individual sites in multivariate environmental (PCoA) space. Horizontal black lines within boxes indicate medians, solid triangles indicate means, and variance is reported with numerical labels. Notches around the medians represent $95 \%$ confidence limits, such that non-overlapping notches between boxplots represent significant differences at the $P<0.05$ level. 


\section{CONCLUSIONS}

We conclude that environmentally, rather than spatially, stratified sampling achieved higher levels of ecological coverage across a continental ecosystem observation network, consistent with previous studies (Austin and Heyligers 1989, Wessels et al. 1998). The spatial sampling of TERN Ausplots derives from a deliberate strategy to maximize environmental coverage and representativeness under a series of pragmatic constraints. Given the diversity of the Australian terrestrial environment, relatively few resources are available to sample and monitor such a vast and often remote landmass. The original bioregional stratification to select representative bioregions for sampling, followed by further stratification within, pragmatic site selection protocols and iterative gap-filling, has proven efficient in this regard.

The environmental coverage of Ausplots is greater than three retrospective sampling schemes that could have been applied to obtain statistically robust and unbiased samples. An alternative stratification based on climatic zones resulted in greater environmental coverage than Ausplots. However, the resulting sample was biased toward more mesic, coastal habitats that are already better sampled by historical monitoring. Targeted gap-filling using a smaller number of complementary sites can now fine tune the ecological coverage of Ausplots (Guerin et al. 2020b).

All potential spatial sampling strategies have advantages and limitations, depending on their intended application. While GRTS is proposed as a spatially balanced method that still allows any location to be selected for sampling, our results suggest that for large, diverse terrestrial regions, it may be useful to combine it with some form of initial bioregional stratification when the number of samples is limited, in order to increase representativeness and environmental coverage. Indeed, such a process is already possible in existing implementations (Kincaid and Olsen 2017).

Our stocktake of the environmental coverage of Ausplots to date compared performance to two benchmarks: (1) the background environment the observation network seeks to represent; and (2) a set of alternative, retrospective sampling strategies. This assessment may be useful as context for interpretation of Ausplots monitoring data, as well as the spatial sampling of other large-scale monitoring networks.

\section{ACKNOWLEDgMENTS}

We thank the Ausplots field team (particularly Emrys Leitch), Wally Guerin, TERN (Australia's Terrestrial Ecosystem Research Network, supported by the Australian government through the National Collaborative Research Infrastructure Strategy), and participants of the stratification workshop May 5-6, 2011 -Jeff Foulkes, Jim Deed, Richard Thackway, Paul Novelley, Craig Baulderstone, Michael Preece, Gary Bastin, Kathy Waters, Stephen van Leeuwen, Russell Grant, Sam Wood, Kathleen Richardson, Greg Chapman, Nikki Thurgate, Teresa Eyre, Mike Flemming, Peter Scarth, Andrew White, and Peter Wilson.

\section{Literature Cited}

Albuquerque, F., and P. Beier. 2018. Improving the use of environmental diversity as a surrogate for species representation. Ecology and Evolution 8:852-858.

Anderson, M. J., K. E. Ellingsen, and B. H. McArdle. 2006. Multivariate dispersion as a measure of beta diversity. Ecology Letters 9:683-693.

Austin, M. P., and P. C. Heyligers. 1989. Vegetation survey design for conservation - gradsect sampling of forests in northeastern New South Wales. Biological Conservation 50:13-32.

Barnett, D. T., et al. 2019. The terrestrial organism and biogeochemistry spatial sampling design for the National Ecological Observatory Network. Ecosphere 10:e02540.

Baruch, Z., S. Caddy-Retalic, G. R. Guerin, B. Sparrow, E. Leitch, A. Tokmakoff, and A. J. Lowe. 2018. Floristic and structural assessment of Australian rangeland vegetation with standardized plot-based surveys. PLOS ONE 13:e0202073.

Bastin, J.-F., et al. 2017. The extent of forest in dryland biomes. Science 356:635-638.

Bruelheide, H., et al. 2018. Global trait-environment relationships of plant communities. Nature Ecology and Evolution 2:1906-1917.

Caddy-Retalic, S., et al. 2017. Bioclimatic transect networks: powerful observatories of ecological change. Ecology and Evolution 7:4607-4619.

Carvalho, S. B., J. Gonçalves, A. Guisan, and J. P. Honrado. 2016. Systematic site selection for multispecies monitoring networks. Journal of Applied Ecology 53:1305-1316.

Christianson, D. S., and C. G. Kaufman. 2016. Effects of sample design and landscape features on a measure of environmental heterogeneity. Methods in Ecology and Evolution 7:770-782. 
Cleverly, J., et al. 2019. TERN, Australia's land observatory: addressing the global challenge of forecasting ecosystem responses to climate variability and change. Environmental Research Letters 14:95004.

Craig, M. A. 2013. Regolith Map of Australia Edition 1. Geoscience Australia, Canberra. http://pid.geoscie nce.gov.au/dataset/ga/75626

Danz, N. P., et al. 2005. Environmentally stratified sampling design for the development of Great Lakes environmental indicators. Environmental Monitoring and Assessment 102:41-65.

Department of the Environment. 2012. Interim Biogeographic Regionalisation for Australia (Subregions) v. 7 (IBRA) [ESRI shapefile]. http://intspat01.ris.e nvironment.gov.au/fed/catalog/search/resource/de tails.page?uuid=\%7BDFB470D2-FA7E-4792-B5240250EC3AF5B3\%7D

Department of the Environment. 2014. Natural areas of Australia - 100 Metre (Digital Dataset). (ed. A.G.D.o.t.E. Canberra). Australian Government, Canberra, Australian Capital Territory, Australia.

ESCAVI (Executive Steering Committee for Australian Vegetation Information). 2003. Australian vegetation attribute manual: National Vegetation Information System, Version 6.0. Department of Environment and Heritage, Canberra, Australian Capital Territory, Australia.

Eyre, T. J., A. Fisher, L. P. Hunt, and A. S. Kutt. 2011. Measure it to better manage it: a biodiversity monitoring framework for the Australian rangelands. Rangeland Journal 33:239-253.

Gallagher, R. V., S. Allen, and I. J. Wright. 2019. Safety margins and adaptive capacity of vegetation to climate change. Scientific Reports 9:8241.

Gallant, J., J. Austin, K. Williams, T. Harwood, D. King, M. Nolan, and K. Mokany. 2018. 9s soil and landform for continental Australia analysis of biodiversity pattern: aggregated from $3 \mathrm{~s}$ data. v1. In CSIRO, editor. Data collection. CSIRO, Canberra.

Goring, S. J., et al. 2016. Novel and lost forests in the upper Midwestern United States, from new estimates of settlement-era composition, stem density, and biomass. PLOS ONE 11:e0151935.

Grundy, M. J., R. V. Rossel, R. D. Searle, P. L. Wilson, C. Chen, and L. J. Gregory. 2015. Soil and landscape grid of Australia. Soil Research 53:835-844.

Guerin, G., T. Saleeba, and A. Tokmakoff. 2020a. ausplotsR: TERN AusPlots analysis package (Archive v1.1) (Version v1.1). Zenodo. https://doi.org/10. 5281/zenodo.3905746

Guerin, G. R., K. J. Williams, E. Leitch, A. J. Lowe, and B. Sparrow. 2020b. Using generalised dissimilarity modelling and targeted field surveys to gap-fill an ecosystem surveillance network. bioRxiv. https:// doi.org/10.1101/2020.06.01.107391

ECOSPHERE www.esajournals.org
Guerin, G. R., B. Sparrow, A. Tokmakoff, A. Smyth, E. Leitch, Z. Baruch, and A. J. Lowe. 2017. Opportunities for integrated ecological analysis across inland Australia with standardised data from AusPlots Rangelands. PLOS ONE 12:e0170137.

Harwood, T., R. Donohue, I. Harman, T. McVicar, N. Ota, J. Perry, and K. Williams. 2016. 9s climatology for continental Australia 1976-2005: summary variables with elevation and radiative adjustment. v1. In CSIRO, editor. Data collection. CSIRO, Canberra.

Hijmans, R. J. 2018. raster: geographic data analysis and modeling. $\mathrm{R}$ package version. https://CRAN.Rproject.org/package=raster

Hoekman, D., et al. 2017. Design for ground beetle abundance and diversity sampling within the National Ecological Observatory Network. Ecosphere 8:e01744.

Hoffman, F. M., J. Kumar, R. T. Mills, and W. W. Hargrove. 2013. Representativeness-based sampling network design for the State of Alaska. Landscape Ecology 28:1567-1586.

Hutchinson, M. F., S. McIntyre, R. J. Hobbs, J. L. Stein, S. Garnett, and J. Kinloch. 2005. Integrating a global agro-climatic classification with bioregional boundaries in Australia. Global Ecology and Biogeography 14:197-212.

Kincaid, T. M., and A. R. Olsen. 2017. spsurvey: spatial survey design and analysis. R Package Version 3.4. https://CRAN.R-project.org/package=spsurvey

Kumar, J., F. M. Hoffman, W. W. Hargrove, and N. Collier. 2016. Understanding the representativeness of FLUXNET for upscaling carbon flux from eddy covariance measurements. Oak Ridge National Lab(ORNL), Oak Ridge, Tennessee, USA.

Lájer, K. 2007. Statistical tests as inappropriate tools for data analysis performed on non-random samples of plant communities. Folia Geobotanica 42:115-122.

Landsberg, J., and G. Crowley. 2004. Monitoring rangeland biodiversity: plants as indicators. Austral Ecology 29:59-77.

Larsen, D. P., A. R. Olsen, and D. L. Stevens. 2008. Using a master sample to integrate stream monitoring programs. Journal of Agricultural, Biological, and Environmental Statistics 13:243-254.

Lemetre, C., J. Maniko, Z. Charlop-Powers, B. Sparrow, A. J. Lowe, and S. F. Brady. 2017. Bacterial natural product biosynthetic domain composition in soil correlates with changes in latitude on a continent-wide scale. Proceedings of the National Academy of Sciences 114:11615-11620.

McCord, S. E., M. Buenemann, J. W. Karl, D. M. Browning, and B. C. Hadley. 2017. Integrating remotely sensed imagery and existing multiscale 
field data to derive rangeland indicators: application of Bayesian additive regression trees. Rangeland Ecology \& Management 70:644-655.

Messer, J. J., R. A. Linthurst, and W. S. Overton. 1991. An EPA program for monitoring ecological status and trends. Environmental Monitoring and Assessment 17:67-78.

Metzger, M. J., D. J. Brus, R. G. H. Bunce, P. D. Carey, J. Gonçalves, J. P. Honrado, R. H. G. Jongman, A. Trabucco, and R. Zomer. 2013. Environmental stratifications as the basis for national, European and global ecological monitoring. Ecological Indicators 33:26-35.

Michaelsen, J., D. S. Schimel, M. A. Friedl, F. W. Davis, and R. C. Dubayah. 1994. Regression tree analysis of satellite and terrain data to guide vegetation sampling and surveys. Journal of Vegetation Science 5:673-686.

Michalcová, D., S. Lvončík, M. Chytrý, and O. Hájek. 2011. Bias in vegetation databases? A comparison of stratified-random and preferential sampling. Journal of Vegetation Science 22:281-291.

Miller, K. M., and B. R. Mitchell. 2014. A new tool for power analysis of fixed plot data: using simulations and mixed effects models to evaluate forest metrics. Ecosphere 5:1-23.

Oksanen, J., et al. 2018. vegan: community Ecology Package. R package version 2.5-3. https://CRAN.Rproject.org/package=vegan

R Core Team. 2016. R: a language and environment for statistical computing (version 3.5. 1) [Computer software]. R Foundation for Statistical Computing, Vienna, Austria.

Roleček, J., M. Chytrý, M. Hájek, S. Lvončík, and L. Tichý. 2007. Sampling design in large-scale vegetation studies: Do not sacrifice ecological thinking to statistical purism!. Folia Geobotanica 42:199-208.

Schimel, D. 2011. The era of continental-scale ecology. Frontiers in Ecology and the Environment 9:311.

Scholes, R. J., et al. 2008. Toward a global biodiversity observing system. Science 321:1044-1045.

Sparrow, B., et al. 2020a. Effective ecological monitoring requires a multi-scaled approach. Biological Reviews 95: 1706-1719. https://doi.org/10.1111/brv. 12636

Sparrow, B., et al. 2020b. A Vegetation and Soil Survey Method for Surveillance Monitoring of Rangeland Environments. Frontiers in Ecology and the Environment 8:157.

Stern, H., G. De Hoedt, and J. Ernst. 2000. Objective classification of Australian climates. Australian Meteorological Magazine 49:87-96.

Stevens, D. L. Jr, and A. R. Olsen. 2004. Spatially balanced sampling of natural resources. Journal of the American Statistical Association 99:262-278.
TERN. 2018. AusPlots ecosystem surveillance monitoring dataset (http://aekos.org.au/collection/adela ide.edu.au/ausplotsrangelands). Obtained via the ausplotsR R package (https://github.com/ternaustralia/ausplotsR).

Thackway, R., and I. Creswell. 1995. An interim biogeographic regionalisation for Australia: a framework for establishing the national system of reserves, Version 4.0. Australian Nature Conservation Agency, Canberra, Australian Capital Territory, Australia.

Tuanmu, M. N., and W. Jetz. 2015. A global, remote sensing-based characterization of terrestrial habitat heterogeneity for biodiversity and ecosystem modelling. Global Ecology and Biogeography 24:13291339.

van Dam-Bates, P., O. Gansell, and B. Robertson. 2018. Using balanced acceptance sampling as a master sample for environmental surveys. Methods in Ecology and Evolution 9:1718-1726.

van Etten, E. J., and J. E. Fox. 2017. Vegetation-environment relationships of the Hamersley Ranges, a mountainous desert of north-west Australia. Folia Geobotanica 52:161-173.

Viscarra Rossel, R., C. Chen, M. Grundy, R. Searle, and D. Clifford. 2014. Soil and Landscape Grid Australia-Wide 3D Soil Property Maps (3" resolution) Release 1. v3. CSIRO. Data Collection. https://doi. org/10.4225/08/5aaf553b63215

Viscarra Rossel, R. A., C. Chen, M. J. Grundy, R. Searle, D. Clifford, and P. H. Campbell. 2015. The Australian three-dimensional soil grid: Australia's contribution to the GlobalSoilMap project. Soil Research 53:845-864.

Viscarra-Rossel, R. A., and C. Chen. 2011. Digitally mapping the information content of visible-near infrared spectra of surficial Australian soils. Remote Sensing of Environment 115:1443-1455.

Ware, C., K. J. Williams, J. O. Harding, B. Hawkins, T. Harwood, G. Manion, G. C. Perkins, and S. Ferrier 2018. Improving biodiversity surrogates for conservation assessment: a test of methods and the value of targeted biological surveys. Diversity and Distributions 24:1333-1346.

Watson, I. A. N., and P. Novelly. 2004. Making the biodiversity monitoring system sustainable: design issues for large-scale monitoring systems. Austral Ecology 29:16-30.

Wessels, K. J., A. S. Van Jaarsveld, J. D. Grimbeek, and M. J. Van der Linde. 1998. An evaluation of the gradsect biological survey method. Biodiversity \& Conservation 7:1093-1121.

White, A., B. Sparrow, E. Leitch, J. Foulkes, R. Flitton, A. J. Lowe, and S. Caddy-Retalic. 2012. AusPlots Rangelands survey protocols manual. Version 
1.2.9. The University of Adelaide Press, Adelaide, South Australia, Australia.

Williams, K., et al. 2010. Harnessing continent-wide biodiversity datasets for prioritising national conservation investment. CSIRO Ecosystem Sciences, Canberra, Australian Capital Territory, Australia.

Williams, K. J., L. Belbin, M. P. Austin, J. Stein, and S. Ferrier. 2012. Which environmental variables should I use in my biodiversity model? International Journal of Geographic Information Sciences 26:2009-2047.
Williamson, G. J., L. Christidis, J. A. Norman, B. W. Brook, B. G. Mackey, and D. M. Bowman. 2011. The use of Australian bioregions as spatial units of analysis to explore relationships between climate and songbird diversity. Pacific Conservation Biology 17:354-360.

Wood, S. W., L. D. Prior, H. C. Stephens, and D. M. Bowman. 2015. Macroecology of Australian tall eucalypt forests: baseline data from a continentalscale permanent plot network. PLOS ONE 10: $\mathrm{e} 0137811$.

\section{Data Availability Statement}

Environmental data are available from the CSIRO Data Access Portal (Harwood et al. 2016, Gallant et al. 2018). TERN Ausplots data are available through ausplotsR (TERN 2018, Guerin et al. 2020a). Extracted environmental data are included in the Supporting Information.

\section{SUPPORTING INFORMATION}

Additional Supporting Information may be found online at: http://onlinelibrary.wiley.com/doi/10.1002/ecs2. 3307/full 